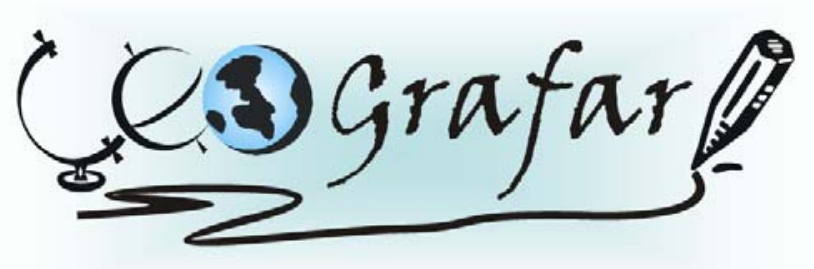

Revista Eletrônica do Programa de Pós-Graduação em Geografla - UFPR

\title{
ORIGEM E DESENVOLVIMENTO DA ECOLOGIA E DA ECOLOGIA DA PAISAGEM
}

\author{
JOÃO CARLOS NUCCI ${ }^{1}$
}

\begin{abstract}
RESUMO
Para alguns as causas da crise atual da humanidade estariam na visão de mundo fragmentada e mecanicista da ciência e que, para descrever apropriadamente um mundo globalmente interligado, seria necessária uma perspectiva ecológica. Assim, a ecologia, para alguns cientistas, para vários educadores e para quase todos os meios de divulgação de massa, vem sendo considerada como uma panacéia capaz de resolver os problemas ambientais, principalmente, por sua possível visão sistêmica da realidade. Para discutir sobre essas colocações este artigo apresenta as origens históricas da Ecologia como ciência e comprova que ainda a Ecologia não conseguiu desenvolver uma visão de conjunto suficiente para enfrentar os problemas ambientais. Com o surgimento da Ecologia da Paisagem, vislumbrou-se a possibilidade de uma maior integração entre as diferentes formas de conhecimento científico, como a Geografia e a Biologia. Apesar dos avanços, o ser humano ainda é muito pouco considerado, mesmo nessa nova ciência que pretende estudar a paisagem, um conceito mais geográfico, de forma ecológica. Conclui-se que em uma civilização na qual o pensamento que fragmenta é valorizado no lugar daquele que une e pensa as relações entre as partes, não se consegue promover oportunidades de comunhão entre especialistas de diferentes áreas do conhecimento. Palavras-chave: ecologia, ecologia da paisagem, paisagem.
\end{abstract}

\section{ORIGIN AND DEVELOPMENT OF ECOLOGY AND LANDSCAPE ECOLOGY}

\begin{abstract}
The causes of humanity current crisis, for some, would be in the fragmented and mechanicist science's world vision and that, to an appropriately description of a globally connected world, would be necessary an ecological perspective. Thus, the ecology, to some scientists, to several educators and to almost all the media, is becoming considered as a panacea able to solve environmental problems, mainly, owning to its pretense systemic approach. This paper introduces the Ecology's historical origins as science and proves that Ecology did not obtain to develop a vision of set enough to face the environmental problems. With the sprouting of the Landscape Ecology, its intended a possibility of a greater connection between different scientific knowledge approach, as Geography and Biology, however, despite of the progress, the human aspects are still few considered, even in this new science that intends to study the landscape, a concept more like geographical, of the ecological approach. This paper concludes that it is impossible to promove chances of union between approaches of different sciences, if the civilization agree only in the fragmented knowledge. Key-words: ecology, landscape ecology, landscape.
\end{abstract}

\footnotetext{
${ }^{1}$ Biólogo (IB-USP), doutor em Geografia Física (DG-FFLCH-USP) e professor do Departamento de Geografia da Universidade Federal do Paraná - UFPR. E-mail: nucci@ufpr.br
} 


\section{INTRODUÇ̃̃̃O}

O ser humano chega ao século XXI em meio a uma série de acontecimentos que colocam em dúvida o seu modo de vida contemporâneo, pois mesmo com todo desenvolvimento tecnológico e econômico percebe-se, claramente, a deterioração do ambiente natural acompanhada de um correspondente aumento nos problemas de saúde física, mental e social dos indivíduos.

Uma possível explicação para esses e para outros problemas da atual civilização foi apontada por Capra (1982) ao afirmar que a sociedade contemporânea encontra-se em uma crise e que essa seria uma crise de visão de mundo:

“(...) nossa sociedade, como um todo, encontra-se em uma crise derivada do fato de que estamos tentando aplicar os conceitos de uma visão de mundo obsoleta - a visão de mundo mecanicista da ciência cartesiana-newtoniana - a uma realidade que já não pode ser entendida em função desses conceitos. Vivemos hoje num mundo globalmente interligado, no qual os fenômenos biológicos, psicológicos, sociais e ambientais são todos interdependentes. Para descrever esse mundo apropriadamente, necessitamos de uma perspectiva ecológica que a visão de mundo cartesiana não nos oferece" (CAPRA, 1982).

A visão cartesiana-newtoniana apresenta como característica a noção de mundo como uma máquina, a descrição matemática da natureza e o método analítico de raciocínio que consiste em decompor pensamentos e problemas em suas partes componentes e em dispôlas em sua ordem lógica.

É interessante colocar que esses procedimentos analíticos só funcionam se as interações entre as partes são inexistentes ou fracas o suficiente para serem negligenciadas em certos propósitos de pesquisa. Somente nestas condições as partes podem ser trabalhadas separadamente, logicamente e matematicamente, para depois serem entendidas no conjunto. A segunda condição é que as relações entre as partes sejam lineares, pois, somente assim, o comportamento do todo pode ser identificado por meio da soma do comportamento de cada parte e processos parciais podem ser sobrepostos para se obter o processo total. Essas condições não são encontradas em entidades intituladas como sistemas. Um sistema é uma organização complexa, sendo caracterizado pela existência de fortes interações ou por interações não triviais, isto é, não lineares (BERTALANFFY, 1993).

Bertalanffy (1993) também reconhece que a visão sistêmica é uma necessidade perante o problema das limitações dos procedimentos analíticos da ciência clássica enunciada por Galileu e Descartes.

Para Capra (1982) as limitações da visão de mundo cartesiana e do sistema de valores em que se assenta, por sua tendência em discriminar, medir e classificar, ou seja, em fragmentar a realidade, estão afetando nossa saúde individual e social. Capra (op cit.) destaca, como exemplos, a atuação da medicina moderna, que se caracteriza pela valorização do corpo humano como uma máquina e das partes cada vez menores desse corpo, negligenciando os aspectos psicológicos, sociais e ambientais da doença e o sistema econômico, colaborando na divulgação da idéia de que as necessidades humanas são ilimitadas, estimulando certas atitudes como a aquisição excessiva de bens materiais, a 
expansão sem barreiras, a competição inescrupulosa e a obsessão pela tecnologia, encorajando, assim, a busca de metas perigosas e não-éticas.

A forma de produção de um conhecimento fragmentado é outro reflexo da visão cartesiana-newtoniana que pode explicar uma parte dos problemas atuais, pois ao se basear em questões isoladas, destrói a complexidade do ambiente.

O sistema educativo fragmenta a realidade, simplifica o complexo, separa o que é inseparável, ignora a multiplicidade e a diversidade. As disciplinas como estão estruturadas eliminam a desordem e as contradições existentes, para dar uma falsa sensação de arrumação (MORIN, 2003).

Para Morin (2000), há inadequação cada vez mais ampla, profunda e grave entre os saberes separados, fragmentados, compartimentados entre disciplinas e, por outro lado, realidades ou problemas cada vez mais polidisciplinares, transversais, multidimensionais, transnacionais, globais, planetários.

“(...) os desenvolvimentos disciplinares das ciências não só trouxeram as vantagens da divisão do trabalho, mas também os inconvenientes da superespecialização, do confinamento e do despedaçamento do saber. Não só produziram o conhecimento e a elucidação, mas também a ignorância e a cegueira (...) os conhecimentos fragmentados só servem para usos técnicos" (MORIN, 2000).

Para tentar solucionar todos os problemas que conduziram o ser humano à atual crise, Capra propõe uma "nova" visão da realidade: a concepção sistêmica da vida.

"O pensamento sistêmico é pensamento de processo; a forma torna-se associada ao processo, a inter-relação à interação, e os opostos são unificados por meio da oscilação. A construção de uma concepção sistêmica da vida deverá também ser subsidiada pelo conhecimento intuitivo que se baseia em uma experiência direta, não-intelectual, da realidade, tendendo a ser sintetizador, holístico e não-linear" (CAPRA, 1982).

Em várias passagens de seu livro, Capra (1982) sugere o termo "ecologia" e seus correlatos, como sinônimo dessa visão sistêmica, podendo ser citados, como exemplos dessas passagens:

“(...) a tecnologia está desintegrando e perturbando seriamente os processos ecológicos que sustentam nosso ambiente natural (...)";

“(...) para descrever esse mundo apropriadamente, necessitamos de uma perspectiva ecológica que a visão de mundo cartesiana não nos oferece”;

“(...) o amplo conceito de saúde necessário à nossa transformação cultural um conceito que inclui dimensões individuais, sociais e ecológicas (...)”.

Também Morin (2000) sugere que a visão sistêmica permitiria uma produção de conhecimento interdisciplinar colocando, como Capra, o termo "ecologia" como sinônimo de visão sistêmica e de holismo: 
"O desenvolvimento da aptidão para contextualizar tende a produzir a emergência de um pensamento 'ecologizante' (...)”;

“Devemos 'ecologizar' as disciplinas (...)".

Não só Capra e Morin, mas, praticamente, todos os meios de divulgação, colocam a "ecologia" como uma panacéia capaz de resolver os problemas ambientais, principalmente, por sua possível visão sistêmica da realidade.

Mas teria a Ecologia intenção e condições de considerar em suas preocupações todas as questões ambientais? Como os profissionais que lidam com os conceitos e teorias da Ciência Ecológica tratam das questões ambientais?

Essas questões estão colocadas, propositadamente, de forma que não haja uma simples e única resposta que encerre a discussão. $\mathrm{O}$ que se pretende, neste artigo, é tentar identificar o local da Ecologia dentro de um espectro polarizado entre o Reducionismo (focalização no indivíduo, nas partes isoladas de um sistema) e o Holismo (compreensão de todas as partes em seu contexto total), conforme Naveh (2000).

Para tanto, este artigo apresenta um breve histórico do século XV ao XIX da origem e evolução da Ecologia como ciência e, em seguida, trata do surgimento da visão sistêmica e do ecossistema e suas implicações, apresentando a Ecologia da Paisagem como uma esperança de estudos que considerem o ser humano, a sociedade e o meio físico como um conjunto e, por final discute a Ecologia no Brasil na atualidade.

É, nesse momento, conveniente citar Chalmers (1993) em se tratando de comparações ou críticas às diferentes teorias:

"Se devemos falar das maneiras em que as teorias devem ser avaliadas ou julgadas, então minha posição é relativista no sentido de que nego que exista algum critério absoluto em relação ao qual estes julgamentos devem ser feitos (pois) Não haverá argumento puramente lógico que demonstre a superioridade de um paradigma sobre outro e que force, assim, um cientista racional a fazer a mudança. Uma das razões por que não é possível tal demonstração é o fato de estar envolvida uma variedade de fatores no julgamento que um cientista faz dos méritos de uma teoria científica. A decisão de um cientista individual dependerá da prioridade que ele dá a esses fatores (...) Uma compreensão das escolhas feitas por um cientista específico requererá uma compreensão daquilo que o cientista valoriza e envolverá uma investigação psicológica (...)”(CHALMERS, 1993).

Esclarece-se, portanto, que a pretensão de se realizar uma reconstrução de uma breve história da Ecologia, bem como das suas linhas contemporâneas de atuação, não estão livres das perspectivas e experiências desse autor na seleção do material. Não se tem a ingenuidade de se chegar a um consenso de opinião em questão tão controvertida. 


\section{BREVE HISTÓRICO DA ECOLOGIA COMO CIÊNCIA}

A Ecologia, uma ciência que tem como unidade de estudo o ecossistema, só pôde ser inaugurada com o surgimento de novas teorias e com uma série de descobertas que serviram, e ainda servem de base para as explicações oriundas do conhecimento ecológico.

A descoberta dos conceitos e princípios sobre o processo de fixação de energia solar e a circulação dos nutrientes, por exemplo, só começou a surgir com a grande mudança da visão mística dos escolásticos para a concepção científica do mundo iniciada no século XVI.

Naquela época Descartes (1596-1650) enfatizou a visão de mundo mecanicista e a separação corpo-alma, o que permitiu a investigação objetiva da anatomia e da fisiologia humanas. $\mathrm{O}$ corpo humano era visto como uma máquina com engrenagens (órgãos do corpo) consideradas de forma isolada e Isaac Newton (Inglaterra - 1642), ao desenvolver uma completa formulação matemática da concepção mecanicista da natureza, deu realidade ao sonho cartesiano e completou a revolução científica.

Os séculos XVI e XVII, portanto, foram marcados por mudanças revolucionárias na física e na astronomia. Todavia, essa revolução na ciência levou à fragmentação do pensamento com reflexos que, até os dias atuais, podem ser verificados na forma de divisão das disciplinas acadêmicas. A visão cartesiana-newtoniana também levou à atitude generalizada de reducionismo na ciência - a crença em que todos os aspectos dos fenômenos complexos podem ser compreendidos se reduzidos às suas partes constituintes.

Constatou-se, na breve revisão da história da ciência, que as ciências ditas exatas, até a primeira metade do século XIX, executaram seus estudos com embasamento teórico e diretriz para a investigação científica dentro de uma postura positivista na qual a mensuração seria um aspecto necessário das investigações científicas, fato que pode ser ilustrado pelo posicionamento de Kelvin (1824-1907), físico irlandês ao afirmar que quando se é possível medir aquilo de que se está falando e expressá-lo em números, então pode-se conhecer algo a respeito; mas quando não se pode medi-lo, quando não se pode expressá-lo em números, o conhecimento é de natureza pobre e insatisfatória.

Entretanto, para aqueles que se voltavam para o estudo da natureza, a preocupação com a quantificação era secundária, sendo o inventário de plantas e animais do planeta considerado a principal tarefa que os naturalistas deveriam abraçar.

Porém, não se tratavam apenas de listas de plantas e animais ou apenas de descrição de paisagens os resultados dos estudos desses naturalistas. A visão integradora e de relações já fazia parte da forma de interpretação da natureza, podendo-se destacar, como exemplo, o médico e geógrafo Alexander von Humboldt (1769-1859), que descrevendo formalmente as relações entre clima, latitude e altitude, chega, em 1805, ao conceito de geobotânica cujo objeto era o estudo das relações das plantas com o ambiente, o que sugere uma visão mais integradora da natureza.

Humboldt, em sua viagem pela América, iniciada em 1799, já tinha uma firme convicção de que era possível descobrir os vínculos existentes entre os seres vivos e a natureza inanimada, estudar suas relações mútuas e explicar como se distribuem no espaço; prestou, também, uma grande atenção na perspectiva histórica, interessando-se pela evolução e 
pelas trocas observáveis na natureza, rompendo-se, assim, com a linha tradicional de pensamento que considerava a natureza como algo estático e imóvel (CAPEL \& URTEGA, 1984).

Os inventários provenientes das observações dos naturalistas viajantes e as explicações resultantes dos trabalhos experimentais, de campo e de laboratório serviram, durante o século XIX, de base para a primeira e a mais importante teoria integradora da biologia, a teoria da evolução.

A primeira teoria científica da evolução foi proposta por Lamarck (1744-1829) em 1809 e se baseava na prevalência dos fatores do meio físico.

Em 1859, Darwin (1809-1882), apresentando uma esmagadora massa de provas, propõe a teoria da evolução com base na influência das relações entre organismos, levando à seleção natural. Darwin chamou a atenção para as infinitas, complexas e ajustadas relações mútuas de todos os organismos entre si e com as condições físicas de existência.

A teoria da evolução opunha-se à noção de um mundo perfeito, ordenado e finalístico, como aquele descrito pelos físicos do século XVIII. Ela trazia em seu bojo a idéia de mudança, crescimento e desenvolvimento que passou a fazer parte do século XIX em diante.

As descobertas de Darwin forçaram os cientistas a abandonarem a concepção cartesiana do mundo na qual a natureza era vista como um sistema mecânico composto de elementos básicos. $\mathrm{O}$ universo, a partir desse momento, devia ser descrito como um sistema formado por estruturas complexas em permanente mudança.

Lamarck e Darwin definiram as duas grandes linhas da ecologia e que são partes de sua definição clássica: o estudo das relações recíprocas dos organismos e destes com o ambiente; surge uma teoria integradora, reunindo conhecimentos e conceitos de vários campos do saber.

Um dos divulgadores das idéias de Darwin, o biólogo alemão, Ernest Heinrich Haeckel (1834-1919), observou em seus estudos que as espécies variavam de acordo com a localização na qual se encontravam e, ao publicar em 1866 o livro "Morfologia Geral dos Organismos", sugeriu o termo "oecologia" para o estudo das relações dos animais e plantas com o ambiente, como um novo campo de pesquisa.

Haeckel considerava a Ecologia como uma ciência que se preocupava em estudar a fisiologia das relações, que seria a história natural científica, e a distinguia da Biogeografia que, para ele, deveria se preocupar com a corologia, ou distribuição dos organismos. Além disso, Haeckel também sugeriu que se prestasse atenção na forma como animais, plantas e humanos são dependentes de seus respectivos ambientes. Essas considerações acabaram por se transformar em uma nova disciplina científica para a qual ele propôs o nome de Ecologia.

Como não poderia ter sido diferente, ao surgir como ciência, a Ecologia procurou se definir perante aos outros campos do saber e, ao fazer isso, restringiu seu campo de ação e, inevitavelmente, restringiu-se com os limites que lhe foram impostos na época. 
“(...) a ênfase dos estudos ecológicos permaneceu centrada na importância dos estudos de fisiologia e na tentativa de implantação da metodologia experimental para o estudo das respostas das plantas e animais à ação direta dos fatores ambientais e, em particular, do ambiente físico. $\mathrm{O}$ apego dos primeiros ecólogos, originalmente de formação em botânica e zoologia, à fisiologia fundamentada na física e na química, sugere que esse movimento emprestava à nova disciplina maior respeitabilidade científica pela introdução de métodos quantitativos e permitia a verificação experimental de hipóteses, padrões da ciência contemporânea" (ÁVILA-PIRES, 1999).

O processo de construção da Ecologia como ciência continuou no século XX. Em 1905, o norte-americano Frederick Edward Clements (1874-1945), um ecologista vegetal, publicou o livro "Métodos de Pesquisa em Ecologia", amplamente recebido pelo mundo AngloSaxão, espalhando a noção de ecologia (GROENING, 2001).

Todavia, no início, a Ecologia, segundo definição de Haeckel, não conseguiu deslanchar e, na passagem do século XIX para o século XX, ainda permanecia com uma visão mais analítica do que sistêmica.

\section{ECOLOGIA, TEORIA GERAL DOS SISTEMAS E ECOSSISTEMA}

No início do século XX, a Ecologia continuava seu caminho para a constituição de uma teoria capaz de fornecer um modelo sistêmico que indicasse uma via de aplicação científica para seus propósitos investigativos. Entretanto, a construção de um novo paradigma, como meio de visualizar a natureza da ciência, não é algo fácil de executar e pode levar anos até que um novo modelo passe a ser aceito pela comunidade científica.

O conceito de sistema não era novo e já fora utilizado por Newton (sistema solar), por Lavoisier (sistemas respiratório, digestivo, circulatório, etc.) entre outros, porém, permaneceu à margem do interesse científico até que o biólogo Ludwig von Bertalanffy, em 1928, ao ampliar a teoria do holismo de Smuts (1926), segundo a qual o universo estaria edificado em estruturas de complexidade crescente - átomos, moléculas, células, indivíduos, sociedades e ecossistemas, abriu uma porta para a utilização do conceito para diferentes disciplinas e campos de atividade humana, como uma teoria geral de sistemas.

Para Bertalanffy (1993), a necessidade de uma visão sistêmica resultou do fato de que o esquema mecanicista mostrava-se insuficiente para tratar os problemas cada vez mais complexos, especialmente nas ciências biológicas e sociais. No início dos anos 20, ele se preocupou com essa lacuna na pesquisa e teoria biológicas e defendeu uma concepção organísmica na biologia cuja ênfase era dada na consideração do organismo como um todo ou sistema.

Pode-se dizer que, mesmo em seus primórdios, a teoria dos sistemas conseguiu influenciar a Ecologia inspirando o surgimento do termo "ecossistema" sugerido por Tansley.

O ecólogo Arthur Tansley, que em 1913 fundou a primeira sociedade de ecologia a British Ecological Society, sugeriu, em 1935, o termo ecossistema como um modelo teórico, salientando-se além da importância do estudo conjunto dos organismos e dos fatores 
inorgânicos como sistemas, que os ecossistemas, para os ecólogos, seriam as unidades fundamentais da natureza na face da terra.

Tansley estava ciente e deixou claro que propunha um modelo abstrato e não uma realidade ecológica, identificável na natureza; entretanto, para aquele momento, foi a visão menos radical e reducionista da organização das comunidades.

Das idéias de Darwin, que propunham que a unidade de sobrevivência seria a espécie, passa-se, agora, para um conceito mais sistêmico no qual a unidade de sobrevivência seria o organismo-em-seu-meio-ambiente.

Porém, apesar dos avanços em busca de uma Ecologia com visão sistêmica, o que se constatava era uma forte influência de pesquisadores especializados e distribuídos em subáreas da Ecologia e com procedimentos muito mais de análise do que de síntese.

Sobre a Ecologia do início do século XX, Clements e Shelford (1939 apud ÁVILA-PIRES, 1999) afirmavam que:

“(...) sua natureza sintética é muito freqüentemente obscurecida por divisões, tais como autoecologia, sinecologia, ecologia de insetos, e ecologia humana (...) Esta situação dificilmente pode ser remediada, exceto substituindo o treinamento atual altamente especializado por um ensino sintético em profundidade. (...) Esta condição perdurará enquanto pesquisadores forem especialistas (...) a verdadeira essência da ecologia é a síntese”.

Em 1949 a preocupação com a visão analítica continua em questão, fato constatado pela observação feita por um grupo de quatro cientistas, incluindo um engenheiro, um sociólogo, um matemático e um biólogo que reclamavam por um método simples e mais unificador para os problemas científicos e por cientistas generalistas (Bode et al, 1949 apud BERTALANFFY, 1993).

Na segunda metade do século XX a Ecologia continuou a lapidação de seus conceitos, princípios e leis com o objetivo de se construir uma teoria.

Em 1957, Margalef introduziu o modelo cibernético, para calcular as transferências tróficas de energia associadas a uma interação reguladora, no estudo dos ecossistemas.

A cibernética está fundamentada na teoria do controle dos sistemas baseada na comunicação (transferência de informação) entre sistema e ambiente e, também dentro do sistema por mecanismos de feedback (BERTALANFFY, 1993).

Em 1968, após 40 anos de estudos, Bertalanffy apresentou sua Teoria Geral dos Sistemas que, apesar de ter suas raízes na concepção organísmica da Biologia, mostrou-se com amplas possibilidades de aplicação em vários campos do conhecimento.

Bertalanffy acreditava que a Biologia seria capaz de substituir a abordagem analítica e mecanicista por uma visão sistêmica, pois sendo essa uma ciência do todo e do organicismo por excelência estaria fadada a desempenhar um papel na nossa visão do mundo que jamais desempenhara antes (BRANCO, 1989). 
O sentido fundamental a ser conservado no conceito de sistema seria o de síntese (palavra que tem exatamente a mesma origem), conjunto unificado, constituído de partes solidárias, de alguma forma articuladas entre si e não reunidas ao acaso; sua dimensão mínima é a de uma organização capaz de funcionar por si só (BRANCO, 1989).

A teoria dos sistemas ressaltou os riscos da visão reducionista na tentativa de se explicar o todo pelo comportamento de uma de suas partes constituintes. Segundo a Teoria Geral dos Sistemas, existem propriedades que só podem ser encontradas na complexidade e que, portanto, não devem ser identificadas por meio de análises ou fragmentação do todo, ou seja, uma organização só pode ser estudada como um sistema, pois o todo é maior do que a soma das partes.

“O axioma holístico, 'o conjunto é mais do que a soma das partes', proposto primeiramente por Smuts $(1926,1971)$ e introduzido na ecologia por Egler (1942) como o conceito de organização hierárquica da natureza, tem se tornado a presunção filosófica básica da Teoria Geral dos Sistemas" (NAVEH E LIEBERMAN, 1984).

Apesar da Teoria dos Sistemas ter fornecido uma abrangência com um enfoque interdisciplinar e, portanto, com uma possibilidade de se relacionar teoria social e econômica às teorias física e biológica, a abordagem empregada na Ecologia durante a segunda metade do século XX, foi a de utilização de sistemas capazes de especificação, análise e manipulação de maneira rigorosa e quantitativa, com modelos matemáticos prometendo transformar a ecologia em uma ciência exata. Um dos textos didáticos mais famosos no campo da Ecologia, o de Eugene Odum (1953, 1959, 1971), encarregou-se de difundir a concepção do ecossistema passível de modelização e análise matemática, ao adotar a metodologia reducionista dos modelos cibernéticos de Margalef (ÁVILA-PIRES, 1999).

No $1^{\circ}$ Congresso Internacional de Ecologia em Haia ocorrido em 1974, ficou estabelecido que o verdadeiro escopo da Ecologia seria o estudo das comunidades ou sinecologia porém, Ávila-Pires (1999) afirma que, até esse momento, o que se podia evidenciar é que muitos estudos ditos ecológicos não passavam de uma simples justaposição de dados colhidos sobre vegetação, fauna, clima e substrato, de forma independente, o que não permitia conhecer o ecossistema, nem sua estrutura nem seu funcionamento.

Para Naveh (2000), a Teoria Geral dos Sistemas, que deveria prover uma visão transdisciplinar do mundo que rompesse as barreiras culturais e ideológicas, nunca teve suas metas alcançadas, apesar de ter aberto um caminho para os atuais conceitos de complexidade.

A Teoria Geral dos Sistemas tem um ponto-de-vista holístico, mas a análise sistêmica é mais estudada do que a síntese (NAVEH \& LIEBERMAN, 1984).

Até mesmo Bertalanffy reconheceu os perigos de um uso discriminado de sua teoria, já que o seu uso inadequado poderia, por exemplo, ao colaborar com uma idéia de um Estado ou Nação como um super organismo, constituir a fundamentação para um estado totalitarista, 
no qual o indivíduo humano apareceria como uma insignificante célula de um organismo ou um trabalhador sem importância (BERTALANFFY, 1993). ${ }^{2}$

Bertalanffy postulou essa nova teoria chamada Teoria Geral dos Sistemas com o objetivo principal de formulação de princípios válidos para todos os sistemas em geral, sejam eles de natureza física, biológica ou social.

"Se definirmos convenientemente o conceito de sistema nós encontraremos os modelos, princípios e leis que podem ser aplicáveis aos sistemas em geral (...), por exemplo, a lei de crescimento exponencial pode ser aplicada para células de bactérias até populações de bactérias, de animais ou de humanos (...) $\mathrm{O}$ mesmo tipo de equação, que descreve a competição de animais e plantas na natureza, pode ser aplicado para descrever a competição no campo da economia. Esta correspondência é devida ao fato dessas entidades poderem ser consideradas como sistemas, isto é, um complexo de elementos em interação" (BERTALANFFY, 1993).

Mas para Leff (2001),

“(...) o propósito de unificação dos discursos científicos, de homogeneização de suas estruturas conceituais, conformou uma prática interdisciplinar fundada numa Teoria Geral dos Sistemas. Seu objetivo unificador e reducionista, compartilhado com o positivismo lógico, reaparece em certas explicações fisicalistas e biologistas dos processos históricos, surgidos do desejo de encontrar um mesmo e único princípio organizador da matéria (...) estes sistemas desconhecem a integridade conceitual de cada ciência".

Na Teoria Geral dos Sistemas os seres humanos não passam de peças de uma engrenagem e são considerados todos como simples elementos com uma mesma responsabilidade. Isso, segundo Leff (2001), encobre as relações de poder e de exploração, fonte de desigualdades entre os companheiros de viagem.

A sistematização do saber, a normalização das ações sociais, a uniformização dos estilos culturais surgem como o signo unitário do regime totalitário do valor de troca que tende a estabelecer seu regime de equivalência recodificando e reduzindo o mundo a objetos similares, equiparáveis. Essa mistificação do mundo, objetivado e coisificado pela intervenção da ciência, reaparece na Teoria Geral dos Sistemas que pretende englobar os diferentes campos do conhecimento sob um signo analógico de identidade, ocultando a especificidade teórica que produz a organização e a integridade conceitual das ciências (LEFF, 2001).

\footnotetext{
${ }^{2}$ Veja Brave New World (O admirável mundo novo - Aldous Huxley, 1932) que nos dá uma projeção do que poderá vir a ser a vida na terra, dentro de 500 anos. Nessa obra Huxley mostra a humanidade classificada em um sistema de castas, alcançado por meio do controle genético e condicionamentos (tratamento nutricional, choques elétricos, sirenes ruidosas e tratamentos durante o sono), que garantiria à sociedade um número suficiente de pessoas subdesenvolvidas, para executarem as tarefas menos agradáveis. Nessa sociedade, organizada como um sistema, o ser humano perde sua individualidade e sua liberdade. Veja, também, HUXLEY, A. (1959) Regresso ao Admirável mundo novo.
} 
Além de todos esses problemas levantados, uma outra característica notável na construção da Ecologia como ciência seria a não consideração do ser humano nos estudos dos ecossistemas.

Heinrich Walter, um dos críticos da escola Clementsiana e dos dogmas de Braun-Blanquet, é considerado o pai da moderna Ecologia na Alemanha, podendo ser considerado, também, uma exceção já que introduziu métodos ecofisiológicos nos estudos de geobotânica e, nestes, enfatizou a necessidade de um tratamento holístico para os fatores ecológicos, incluindo os antropogênicos (Walter, 1960 apud NAVEH \& LIEBERMAN, 1984).

Essa exclusão do ser humano dos assuntos da Ecologia pode ser esclarecida pelos dizeres de Branco (1989) ao considerar que

“(...) o ser humano desenvolve comportamentos por vezes incompatíveis com os ecossistemas, destruindo-os, porém sem destruir-se. O homem, embora tenha sido originado pelos mesmos princípios da seleção natural, não mais se submete a ela, não pertencendo a qualquer ecossistema em particular" (grifo nosso).

Ainda para Branco (1989):

"O caráter finalista, que não é reconhecido em relação à evolução natural das espécies e dos ecossistemas, passa a constituir principal agente da evolução ou das transformações ambientais, caracterizando o chamado Meio Ambiente (um ambiente antrópico) como significativamente diferente do Ecossistema natural e o estudo do meio ambiente como algo sensivelmente diverso da Ecologia".

Portanto, para Branco, meio ambiente não é sinônimo de ecossistema. O meio ambiente inclui o elemento antrópico e tecnológico enquanto que o ecossistema, tal como definido, com suas características homeostáticas, de controle e de evolução natural não comporta o homem, a não ser em seus estágios primitivos, pois é incompatível com o finalismo e a deliberação característica desta espécie.

Todavia, outros cientistas apresentam visão diferenciada da questão, fato que pode ser exemplificado nos estudos ecológicos em áreas urbanizadas.

Para muitos cidade e natureza devem ser considerados conceitos opostos. A cidade representaria um meio adaptado às necessidades da espécie humana, sendo que a urbanização se caracterizaria pela substituição dos ecossistemas naturais por centros de grande densidade criados pelo homem, onde a espécie dominante seria a humana e o meio estaria organizado para permitir a sua sobrevivência (NUCCI et al., 2003).

Branco (1989) afirma que as cidades, em se tratando de um sistema de base essencialmente (necessariamente) cultural e, por conseguinte, de origem antropogênica e não originado pelas forças seletivas da natureza, não se constitui em um ecossistema, mas para Delpoux (1974) a cidade poderia ser considerada como um ecossistema desequilibrado.

Tratando-se da paisagem urbanizada, o professor Dr. Felisberto Cavalheiro enfatiza que as cidades têm que ser enfocadas tanto nos estudos sociais e de engenharia como nos de 
ecologia de forma integrada, evitando-se entender somente as partes de uma forma cartesiana absoluta (NUCCI, 2001).

Para Sukopp e Werner (1991), expoentes no reconhecimento da importância da conservação da natureza nos assentamentos humanos, a cidade deve mostrar as condições ideais para a conservação da natureza e da paisagem, porém, a descrição do ecossistema urbano, feita por Sukopp (1973), é criticada por representar a cidade ecologicamente ideal, destituída de quaisquer relações e realizações humanas. "Como no final do século XIX, alguns ecólogos do final do século XX viram as grandes cidades como elementos de destruição para aquilo que eles consideravam natureza" (GROENING, 2001).

Se introduzir o ser humano nos estudos dos ecossistemas parece ser complicado, o contrário também trouxe sérios problemas. Nas décadas de 20 e 30, sociólogos norteamericanos propuseram uma Ecologia Humana. Essa disciplina surgiu impulsionada por autores como Robert E. Park, Ernest W. Burgess e R. D. Mackenzie, pertencentes à chamada Escola de Chicago, a cidade na qual se desenvolvia a maioria das investigações. Essa Escola aplicou os conceitos ecológicos e biológicos - sucessão, invasão, simbiose, etc., na análise de questões sócio-econômicas. Burguess e Park tinham a opinião de que era preciso aplicar ao estudo das comunidades humanas o esquema teórico da ecologia vegetal e animal. Essas teorias foram criticadas pelo seu abuso de analogias biológicas, que poderiam servir como justificativa de uma determinada ordem social ao "naturalizar" os problemas urbanos (CAPEL \& URTEGA, 1984).

Para Morin (2000),

"Em um certo sentido, tudo é físico, mas, ao mesmo tempo, tudo é humano. O grande problema, pois, é encontrar a difícil via da interarticulação entre as ciências, que têm, cada uma delas, não apenas sua linguagem própria, mas também conceitos fundamentais que não podem ser transferidos de uma linguagem à outra".

\section{ECOLOGIA DA PAISAGEM}

Como uma esperança de estudos que pudessem considerar o ser humano, a sociedade e o meio físico como um conjunto, surge, em meados do século XX, a Ecologia da Paisagem, com raízes na Europa Central e Ocidental, sendo a Alemanha e a Holanda os primeiros países com a maior quantidade de trabalhos produzidos nessa área. Com o primeiro trabalho sobre o tema escrito em inglês por Naveh e Lieberman (1984), a Ecologia da Paisagem foi introduzida nos EUA e em outros países de língua inglesa.

O termo Ecologia da Paisagem, como uma disciplina científica emergente, foi cunhado por Troll em 1939, ao estudar questões relacionadas ao uso da terra por meio de fotografias aéreas e interpretação das paisagens.

Com a sugestão desse termo Troll teve a intenção de incentivar uma colaboração entre a Geografia e a Ecologia, combinando, assim, na prática, a aproximação "horizontal" do geógrafo examinando a interação espacial dos fenômenos, com a aproximação "vertical" 
dos ecólogos, no estudo das interações funcionais de um dado lugar, ou "ecótopo" (NAVEH \& LIEBERMAN, 1984).

Segundo Zonneveld (1990), a Ecologia da Paisagem de Troll foi uma tentativa de casamento entre a Geografia (paisagem) e a Biologia (Ecologia).

"Paisagem" foi introduzido como termo científico-geográfico no início do século XIX por A. von Humboldt, o grande pioneiro da moderna geobotânica e geografia física. Na língua alemã, o termo paisagem (Landschaft) contém uma conotação geográfico-espacial no prefixo "land", diferentemente da paisagem com significado de cenário encontrado nas artes e na literatura. Os biogeógrafos europeus viram a paisagem não apenas como uma visão estética (como a maioria dos arquitetos da paisagem), ou como parte do ambiente físico (como a maioria dos geógrafos), mas como uma entidade espacial e visual da totalidade do espaço de vida humano, integrando geosfera, biosfera e noosfera (grego "noos" - mente).

Entre os anos de 1945 e 1975, surgiram várias pesquisas nessa área, como, por exemplo, os trabalhos de Neef (1956, 1967 apud LESER, 1992) que salientavam o caráter interdisciplinar dessa abordagem. Geógrafos e Ecólogos na Europa Central, após a II Guerra Mundial, procuravam construir uma noção de Ecologia da Paisagem como uma ciência interdisciplinar que conduzisse a um inter-relacionamento entre a sociedade humana e seu espaço de vida - suas paisagens construídas ou não. Profissionais das mais diversas áreas se uniram com a intenção de se criar uma ponte entre o sistema natural, o rural e o urbano.

Em 1981 realizou-se em Wageningen (Holanda) o $1^{\circ}$ Congresso Internacional de Ecologia da Paisagem, organizado pela The Netherlands Society of Landscape Ecology, que conduziu a criação da Internacional Association of Landscape Ecology (IALE) em 1984.

Durante o congresso, entre as várias definições para a Ecologia da Paisagem, a mais ampla e compreensível definição foi apresentada por Isaak S. Zonneveld, o primeiro presidente da IALE: a ecologia da paisagem deveria ser considerada como uma ciência Bio-GeoHumana e com abordagem, atitude e pensamento holísticos, (Zonneveld, 1982 apud NAVEH, 2000); considerando-se o termo "holístico" como uma total integração do natural com o elaborado pelo homem.

Uma importante contribuição para esse campo foi o estabelecimento de áreas especiais para a Ecologia da Paisagem nas principais universidades da Alemanha com o objetivo de se considerar o complexo inter-relacionamento entre o homem e suas paisagens naturais,

\footnotetext{
${ }^{3}$ A Noosfera pode ser vista como a "esfera do pensamento humano", sendo uma definição derivada da palavra grega vov (nous, "mente") em um sentido semelhante à atmosfera e biosfera. Na teoria original de Vernadsky, a noosfera seria a terceira etapa no desenvolvimento da Terra, depois da geosfera (matéria inanimada) e da biosfera (vida biológica). O conceito da noosfera é atribuído ao filósofo francês Teilhard de Chardin. Segundo ele, assim como há a atmosfera, a geosfera e biosfera, existe também o mundo ou esfera das idéias, formado por produtos culturais, pelo espírito, linguagens, teorias e conhecimentos. Seguindo esta linha de pensamento, alimentamos a noosfera quando pensamos e nos comunicamos. A partir de então, o conceito de noosfera foi revisto e conseqüentemente sendo previsto como o próximo degrau evolutivo de nosso mundo, após sua passagem pelas posteriores transformações de geosfera, biosfera, "tecnosfera" (temporária e em andamento) e, então, a noosfera. Disponível em: http://pt.wikipedia.org/wiki/Noosfera. Acesso em: 02.04.2007.
} 
culturais e industriais, com a inclusão das demandas naturais, culturais e sócio-econômicas e, ao mesmo tempo, o enriquecimento do ambiente biótico natural.

Naveh e Liebernam (1984) afirmam que, com a Ecologia da Paisagem, novas fronteiras foram traçadas em relação à Teoria Geral dos Sistemas; esses autores sugeriram um novo conceito o Total Human Ecosystem (THE) - como um supersistema físico-geosférico, mental e espiritual, no qual os homens seriam integrados com seu ambiente total, e que este deveria ser considerado o maior paradigma holístico da Ecologia da Paisagem. O THE seria considerado o mais alto nível de integração ecológica.

A Ecologia da Paisagem é vista na Europa como uma base científica para o planejamento, manejo, conservação, desenvolvimento e melhoria da paisagem. Ela sobrepujou os objetivos puramente naturais da bioecologia clássica e tem tentado incluir as áreas nas quais o ser humano é o centro da questão - sociopsicologia, economia, geografia e cultura (NAVEH \& LIEBERMAN, 1984).

Entretanto, constata-se uma insatisfação com a atual Ecologia da Paisagem quando Naveh (2000) coloca a necessidade, ainda em questão, da inclusão do ser humano e sua dimensão cultural-social e econômica como parte integral de uma ecologia global e que, perante os desafios de salvaguardar e criar sustentabilidade, saúde, paisagens produtivas e atrativas para o próximo milênio, a Ecologia da Paisagem necessitaria de uma concepção bem mais holística.

Afirma também, que há ainda um considerável número de ecologistas da paisagem que se agarra em um paradigma mecanicista e reducionista, acreditando que a Ecologia da Paisagem somente poderá alcançar uma "maturidade científica" se for capaz de fazer predições exatas dentro de uma visão mecanicista, como a Física (NAVEH, 2000).

Para Morin (2000), prender-se ao axioma de Galileu no qual os fenômenos só devem ser descritos com a ajuda de quantidades mensuráveis, é condenar todo conceito que não seja traduzido por uma medida: "Ora, nem o ser, nem a existência, nem o sujeito podem ser expressos matematicamente ou por meio de fórmulas".

Até mesmo Bertalanffy concorda com uma certa incongruência entre modelo e realidade.

"Existem modelos matematicamente muito sofisticados, mas que são dúbios quando são aplicados em casos concretos; existem problemas fundamentais para os quais técnicas não-matemáticas são mais adequadas (...) seria melhor um modelo não-matemático (verbal) do que iniciar com um modelo matemático e, assim, possivelmente, restringir o campo de visão" (BERTALANFFY, 1993).

A Ecologia da Paisagem muitas vezes, principalmente na escola americana, exclui propositadamente os ser humano de suas pesquisas.

Forman (1995), em um trabalho de 632 páginas sobre Ecologia da Paisagem, afirma logo de início que a ênfase será dada nos processos naturais (relevo, solo, clima, água, fogo, planta e animal) e não nos aspectos das ciências sociais e das humanidades.

Pearson (2002), em um capítulo de livro que se propõe a ensinar conceitos e técnicas em Ecologia da Paisagem, justifica sua escolha por modelos de paisagens, utilizando mapas de 
cobertura da terra, interpretados sob a perspectiva de diferentes espécies (excluindo a humana), pois, sendo os mapas produtos humanos estes apresentam uma perspectiva antropocêntrica, tendendo a se reportarem às necessidades humanas e aos sistemas econômicos, como, por exemplo, ao uso da terra, ao arruamento, às cidades, aos limites políticos e, portanto, não refletem as características importantes da vida selvagem.

\section{ECOLOGIA E ECOLOGIA DA PAISAGEM NO BRASIL}

No Brasil, o primeiro, e talvez até o momento o único, curso de graduação em Ecologia em Universidade Pública, foi criado em 1976 no Instituto de Biociências da UNESP - Rio Claro/SP, sendo reconhecido pelo Ministério da Educação em 1981. Esse curso apresenta como proposta a preparação de profissionais capacitados para o reconhecimento da estrutura e funcionamento de ecossistemas naturais e, com base neste conhecimento, identificar problemas causados pelas atividades humanas e encontrar soluções adequadas para resolvê-los. Sua grade curricular, implantada em 1995, abrange ampla variedade de áreas do conhecimento básico (ciências biológicas, ciências da terra, ciências exatas e ciências humanas). Considera a Ecologia uma ciência multidisciplinar, englobando ciências como a Zoologia, Botânica, Genética, Etologia, Geociências, Microbiologia, Ciências Sociais e Estatística (UNESP, 2004).

Diferentemente da Ecologia na graduação, os cursos de pós-graduação nessa área são muitos e podem ser encontrados em diferentes partes do Brasil. Em uma busca parcial por meio da Internet, constatou-se que os cursos de pós-graduação em Ecologia enfatizam bem mais as disciplinas das Ciências Biológicas, com algumas referências às Ciências Exatas e quase nenhuma disciplina das Ciências Sociais em seus currículos.

Da consulta, por meio da Internet, das propostas e da grade curricular de alguns desses cursos, bem como de uma breve consulta aos títulos dos trabalhos de teses, dissertações e publicações, tanto em nível de graduação quanto de pós-graduação, tem-se a percepção de que o ser humano e a sociedade são sempre vistos apenas como agentes que pressionam os recursos naturais, eliminam espécies e ecossistemas, comprometem os serviços oferecidos pela biosfera (fornecimento de água, a estabilidade climática e a disponibilidade de recursos alimentares), causam impactos, como poluição do ar, da água e do solo, provocam a fragmentação de florestas, o aquecimento global, etc., ou seja, remetendo-se às palavras do professor Monteiro: “(...) o homem - parte integrante da natureza - tende a ser visto como 'vilão', responsável pela destruição da natureza” (MONTEIRO, 1978).

Morin (2000) afirma que a Ecologia recorre a múltiplas disciplinas físicas e biológicas e que, além disso, também precisa recorrer às ciências humanas para analisar as interações entre o mundo humano e a biosfera. Porém, a incorporação das questões humanas nas preocupações da Ecologia trata-se, pelo menos até o momento, de uma intenção, pois, como já mencionado, percebe-se que os trabalhos publicados e as linhas de pesquisa raramente se voltam para as questões do ser humano e da sociedade, salvo em áreas como Etnobiologia, Ecologia Humana e Educação Ambiental.

Também na disciplina Ecologia ministrada nos cursos de Ciências Biológicas, os conteúdos curriculares básicos devem tratar das "(...) relações entre os seres vivos e destes com o ambiente ao longo do tempo geológico. Conhecimento da dinâmica das populações, 
comunidades e ecossistemas, da conservação e manejo da fauna e flora e da relação saúde, educação e ambiente" (BRASIL, 2002).

Conseqüentemente, nos livros didáticos para o Ensino Fundamental e Médio como também em livros adotados nos níveis de graduação e pós-graduação, a ênfase é dada na estrutura e no funcionamento dos ecossistemas, colocando a sociedade somente como uma receptora das informações geradas pelas pesquisas que procuram desenvolver conceitos e valores sobre a importância da conservação da natureza.

De um rápido levantamento dos títulos das pesquisas publicadas no Caderno de Programas do VI Congresso de Ecologia do Brasil, realizado em 2003 na cidade de Fortaleza, constatou-se que dos 1.324 trabalhos, aproximadamente apenas $2 \%$ estão relacionados diretamente com questões sócio-econômicas.

Como visto anteriormente, a Ecologia até meados do século $\mathrm{XX}$ ainda não conseguia elaborar trabalhos com uma visão sintética, devido à existência de muitas subdivisões e de seu corpo de pesquisadores com formação muito verticalizada (Clements e Shelford, 1939 apud ÁVILA-PIRES 1999).

Bertalanffy (1993) explica que a ciência moderna é caracterizada por sua crescente especialização, necessidade de uma enorme quantidade de dados, de complexidade de técnicas e de estruturas teóricas dentro de cada campo. Assim, a ciência é dividida em inúmeras disciplinas que continuamente geram outras novas subdisciplinas. Conseqüentemente, o físico, o biólogo, o psicólogo e o cientista social são encapsulados em seus universos privados, sendo muito difícil trocarem palavras de um "casulo" para outro.

Essas considerações feitas na primeira metade do século XX podem ser resgatadas e comparadas com a situação em que se encontra a Ecologia do início do século XXI. Na atualidade, pode-se considerar que a situação vem se tornando cada vez mais complexa com as inúmeras áreas de atividades previstas para a Ecologia, como pode ser verificado ao se consultar a Resolução n ${ }^{0} 5$ de 02.09.96 do Conselho Regional de Biologia (anexo 1).

Portanto, se a ciência ecológica pôde não somente utilizar os serviços de diferentes disciplinas, mas também criar cientistas policompetentes, como afirma Morin (2000), no Brasil isso parece não acontecer, pois a tendência ainda continua sendo a de formação de especialistas.

Recentemente, também a Ecologia da Paisagem, que havia surgido como uma ciência BioGeo-Humana e com abordagem, atitude e pensamento holísticos (Zonneveld, 1982 apud NAVEH, 2000), passou a ser considerada como uma subárea do conhecimento do Biólogo (CRB, 2003 - anexo 2).

Porém, resgatando-se, novamente, os anais do VI Congresso de Ecologia do Brasil, podese perceber que os trabalhos apresentados na área da Ecologia da Paisagem carregam, principalmente, a visão da escola americana quantitativa e voltada somente para os aspectos biológicos onde o ser humano quase nunca tem vez, com as limitações conceituais e metodológicas já discutidas anteriormente neste artigo. 
A Ecologia da Paisagem deveria dar sua colaboração ao planejamento em geral, inclusive ao planejamento urbano, e não ficar apenas restrito ao estudo das unidades naturais (KLINK, 1981). Essa área do conhecimento, que surgiu com a integração de duas importantes ciências, a Ecologia e a Geografia, poderia ser trabalhada como um aglutinador de diferentes disciplinas com o objetivo de entendimento da complexidade do ambiente, assim, quem sabe não se poderia aventar por uma possível "unidade teóricometodológica" como coloca Monteiro (1978).

Não se pretende, é claro, desprezar quaisquer pesquisas sejam elas mais integradoras ou mais analíticas, pois, as duas visões de mundo são necessárias e se justificadas dentro da teoria adotada, já apresentam uma suficiente razão de ser. Então, a eleição de uma unidade teórico-metodológica não passaria pela eliminação de teorias, nem pela escolha de uma ou outra e nem pela simples união de diferentes teorias, mesmo porque, de acordo com a "tese da incomensurabilidade" de Kuhn, sabe-se que

“(...) frente a duas ou mais teorias rivais, é impossível justificar racionalmente a preferência por uma delas. Isto porque, quando um paradigma é substituído por outro, ocorrem mudanças radicais na maneira de interpretar os fenômenos, nos critérios para selecionar os problemas relevantes, nos procedimentos e técnicas para resolvê-los e nos critérios de avaliação de teorias. Além disso, os conceitos e enunciados de um paradigma não são traduzíveis para outro, pois uma mesma palavra pode corresponder a significados diferentes em diferentes teorias ou paradigmas" (Kuhn 1970 apud ALVES-MAZZOTTI \& GEWANDSZNAJDER, 2001).

As dificuldades para se alcançar essa "unidade teórico-metodológica" se justificam com a mesma explicação que Morin utiliza para o sistema educacional, ou seja, pelo modelo da especialização fechada que formam as mentes tornando insensato um conhecimento para além de uma especialização.

"Tanto no campo da pesquisa quanto no da educação, as resistências são inacreditáveis, os mecanismos são rígidos, inflexíveis, fechados e burocratizados (...) Estes (os professores), como dizia Curien, são como os lobos que urinam para marcar seu território e mordem os que nele penetram" (MORIN, 2000).

Monteiro (1978) afirma que nossa tradição em realizar pesquisas em equipe, é muito reduzida, especialmente aquelas que se projetam multidisciplinarmente. Mas, a única maneira de atingir esse objetivo será o de procurar romper as barreiras que o cercam.

Uma tentativa de se romper essas barreiras que atravancam os estudos no campo das preocupações ambientais, aconteceu no I Fórum de Debates sobre Ecologia da Paisagem e Planejamento Ambiental, realizado em Rio Claro/SP em junho de 2000 e presidido por Felisberto Cavalheiro ${ }^{4}$.

\footnotetext{
${ }^{4}$ O professor doutor Felisberto Cavalheiro (1945-2003) atuou no Departamento de Geografia (FFLCH-USP) e transitava muito bem pelas diferentes áreas que tratam da questão ambiental, entre elas a Geografia, a Ecologia, a Agronomia e a Arquitetura.

Nos anos 90 voltou parte de suas preocupações para um resgate, principalmente, dos estudos alemães sobre paisagem, presidindo em 2000 o I Fórum de Debates sobre Ecologia da Paisagem (Rio Claro/SP). Desde então, a Ecologia da Paisagem passou a fazer parte dos Congressos Brasileiros de Ecologia como área de divulgação de trabalhos.
} 
A diversidade de profissionais convidados, muitos conhecidos internacionalmente, para as conferências, mesas redondas e debates, bem como a oportunidade para a exposição de trabalhos de alunos, principalmente de pós-graduação, de professores e outros pesquisadores, presença de representantes de diferentes comunidades, políticos e a oportunidade de, também, vivenciar concretamente as belas paisagens da região, por meio de excursões, fizeram do I Fórum um marco da Ecologia da Paisagem no Brasil (vide programação do Fórum - anexo 3).

Mas, infelizmente, o movimento corporativista, os interesses econômicos e a formação ainda cartesiana presente em muitas áreas, não permitem que as idéias lançadas naquela ocasião floresçam sem dificuldades.

É necessário compreender que, como coloca Leff “A complexidade ambiental incorpora um processo de construção coletiva do saber (...) A pedagogia da complexidade ambiental abre o encontro infinito de seres diversos dialogando a partir de suas identidades e diferenças" (LEFF, 2001).

\section{CONSIDERAÇÕES FINAIS}

O breve resgate histórico da Ecologia como Ciência mostrou que sua origem se deu com o avanço de descobertas nas ciências exatas (Física e Química) entre os séculos XVII e XX e com os estudos realizados pelos naturalistas, botânicos e zoólogos do século XIX. No início a ênfase dos estudos ecológicos permaneceu centrada na importância dos estudos de fisiologia fundamentada na física e na química e dentro de uma visão mecanicista.

Mesmo com a influência da Teoria Geral dos Sistemas, formulada no século XX como uma alternativa, já que o esquema mecanicista mostrava-se insuficiente para tratar os problemas cada vez mais complexos, constatou-se que os estudos ecológicos, apesar de se modificarem para uma visão menos radical e reducionista, continuavam com os procedimentos muito mais de análise do que de síntese, e com o aprofundamento na manipulação de maneira rigorosa e quantitativa.

No Brasil atual a Ecologia como disciplina, como curso de graduação e de pós-graduação e a existente nos livros didáticos, continua apresentando uma maior influência das Ciências Biológicas e das Ciências Exatas, com forte conotação sistêmica e quantitativa e com muito pouca consideração para com as Ciências Sociais, sendo o lugar do ser humano reservado para o papel de "vilão", pois é encarado como aquele que pressiona os recursos naturais, elimina espécies e ecossistemas. Como uma ciência moderna, a Ecologia é caracterizada por sua crescente especialização, apresentando inúmeras e crescentes subdisciplinas e áreas de atividades.

No sentido inverso dessa especialização e na tentativa de sobrepujar os objetivos puramente naturais da bioecologia clássica e incluir as áreas nas quais o ser humano é o centro da questão, surgiu em meados do século XX a Ecologia da Paisagem, como uma ciência Bio-Geo-Humana, com abordagem, atitude e pensamento holísticos, e fornecendo base científica para o planejamento, manejo, conservação, desenvolvimento e melhoria da paisagem. 
Todavia, a oportunidade de aglutinação de diferentes disciplinas, poucas vezes disponível na história das ciências, está correndo o risco de ser perdida com a transformação da Ecologia da Paisagem em uma sub-disciplina ou sub-área da Ecologia, com exclusão proposital do ser humano de suas pesquisas, além de ainda se embasar no paradigma mecanicista e reducionista, acreditando que a Ecologia da Paisagem somente poderá alcançar uma "maturidade científica" se for capaz de fazer predições exatas dentro de uma visão mecanicista.

De tudo o que foi dito, conclui-se que a perspectiva ecológica sugerida por Capra (1982) e que consideraria os fenômenos biológicos, psicológicos, sociais e ambientais como interdependentes, ainda não existe.

Está claro que a Ecologia apresenta limitações no tocante aos aspectos de uma visão sistêmica e/ou holística, portanto, deve-se repensar o uso do termo "ecologia" e seus derivados como uma oposição ao método científico, ao pensamento racional, analítico, linear como sugere Morin (2000).

A Ecologia não pode e nem pretende dar respostas para as questões sociais, econômicas, espirituais, culturais, por exemplo, pois estas não fazem parte do raciocínio ecológico.

Além disso, acredita-se que nenhuma ciência em particular teria condições de sozinha resolver os problemas da complexidade do mundo de hoje. A eleição de uma única teoria para explicar o mundo parece ser um equívoco. Até mesmo a nova visão da realidade - a concepção sistêmica da vida - proposta por Capra (1982) pode ser criticada por reduzir todas as questões humanas e da sociedade a peças de engrenagens controladas por mecanismos de retroalimentação.

É interessante lembrar a constante tendência de todos os tempos em se considerar o ser humano como uma máquina: primeiro como uma máquina somente mecânica, com alavancas (músculos e ossos) e uma bomba (coração), depois como uma máquina quimiodinâmica, transformando diretamente a energia do combustível (alimento) em trabalho efetivo, mais tarde, como uma máquina auto-reguladora semelhante ao funcionamento de um termostato apresentando uma homeostase mantida por mecanismos cibernéticos e, finalmente, como uma máquina molecular com "usinas de energia" (mitocôndrias) e produção em série de moléculas de proteínas executadas por reações enzimáticas com base em códigos genéticos (BERTALANFFY, 1993). Mas como coloca o próprio Bertalanffy, apesar de seu sucesso, o modelo do organismo como máquina tem suas dificuldades e limitações.

A visão de relações, necessária para um possível entendimento da complexidade do mundo, dificilmente pode ser desenvolvida em uma civilização que dá maior importância para a separação em detrimento da ligação, e para a análise em detrimento da síntese. $\mathrm{O}$ pensamento que fragmenta é valorizado no lugar daquele que une e pensa as relações entre as partes.

Talvez o mais sensato para essa questão, seria a promoção de oportunidades de comunhão entre especialistas de diferentes áreas do conhecimento, mas, para isso, seriam necessárias humildade e iniciativa para o rompimento das barreiras impostas pelo atual sistema. 
A troca de conhecimento, o trabalho em equipes multidisciplinares e a utilização de conceitos e teorias mais integradoras trariam uma possibilidade de um melhor entendimento e posicionamento perante as questões relacionadas com a complexidade do mundo.

\section{REFERÊNCIAS}

ALVES-MAZZOTTI, A.J.; GEWANDSZNAJDER, F. O método nas ciências naturais e sociais: pesquisa quantitativa e qualitativa. São Paulo: Pioneira, 2001, 203p.

ÁVILA-PIRES, F. D. de. Fundamentos históricos da ecologia. Ribeirão Preto: Holos, $1999,278 p$.

BERTALANFFY, L. von. General System Theory. Foundations, development, applications. New York: George Braziller, 1993, $11^{\mathrm{a}}$ ed. (1 ${ }^{\mathrm{a}}$ ed. 1968), 295p.

BRANCO, S.M. Ecossistêmica: uma abordagem integrada dos problemas do meio ambiente. São Paulo: Edgard Blücher, 1989, 141p.

BRASIL - Ministério da Educação. Resolução CNE/CP n. 7, de 11/03/2002 (Estabelece as Diretrizes Curriculares para os Cursos de Ciências Biológicas). In: Biologia. Jornal do Conselho Regional de Biologia, Ano IX, n. 114, São Paulo: CRB, maio de 2004.

CAPEL, H.; URTEGA, L. Las nuevas geografias. Madrid: Aula Abierta Salvat, 1984, $64 \mathrm{p}$.

CAPRA, F. O Ponto de Mutação. São Paulo: Cultrix, 1982, 447p.

CHALMERS, A.F. O que é ciência afinal? São Paulo: brasiliense, 1993, 225p.

DELPOUX, M. Ecossistema e Paisagem. Métodos em Questão 7, São Paulo: Instituto de Geografia - USP, 1974, 23p. (Trad. Modenesi. $1^{\mathrm{a}}$. Ed. 1972)

FORMAN, R.T.T. Land mosaics. The ecology of landscapes and regions. New York: Cambridge University Press, 1995, 632p.

GROENING, G. About the professional reach of garden culture and open space development in Germany. GEOUSP, 9, São Paulo: DG-FFLCH-USP, 2001, pp. 163-171.

HABER, W. Using Landscape Ecology in Planning and Management. In: ZONNEVELD, I.S.; FORMAN, R.T.T. (Eds.) Changing Landscapes: an ecological perspective. New York: Springer-Verlag, 1990, 286p.

KLINK, H.J. Geoecologia e regionalização natural (bases para Pesquisa Ambiental). Biogeografia 17, São Paulo: Instituto de Geografia - USP, 1981. 
LEFF, E. Epistemologia ambiental. São Paulo: Cortez, 2001, 240p.

LESER, H. Landscape Ecology. In: Ehlers, E. (Ed.) 40 Years After: German Geography. Developments, trends and prospects 1952-1992, Bonn/Tübingen: Institute for Scientific Co-operation, 1992 p. 99-126.

MONTEIRO, C.A.F. Derivações antropogênicas dos geossistemas terrestres no Brasil e alterações climáticas: perspectivas urbanas e agrárias ao problema da elaboração de modelos de avaliação. SIMPÓSIO SOBRE A COMUNIDADE VEGETAL COMO UNIDADE BIOLÓGICA, TURÍSTICA E ECONÔMICA. Anais ... São Paulo: ACIESP n ${ }^{\circ}$ 15, 1978, p. 43-74.

MORIN, E. A cabeça bem-feita: repensar a reforma - reformar o pensamento. Rio de Janeiro: Bertrand Brasil, 2000, 128p.

MORIN, E. A escola mata a curiosidade. Entrevista para Revista Nova Escola. Disponível em: http://novaescola.abril.com.br/index.htm?ed/168 dez03/html/falamestre. Acesso em: dez./2003.

NAVEH, Z. What is holistic landscape ecology? A conceptual introduction. Landscape and Urban Planning 50 (7-26), 2000.

NAVEH, Z.; LIEBERMAN, A.S. Landscape Ecology - Theory and Application. New York / Berlin / Heidelberg / Tokyo: Springer Series on Environmental Management, 1984.

NUCCI, J.C. Qualidade ambiental e adensamento urbano. São Paulo: Humanitas/FAPESP, 2001, 236p.

NUCCI, J.C.; BUCCHERI FILHO, A.T.; NEVES, D.L.; OLIVEIRA, F.A.H.D.; KRÖKER, R. Carta de Hemerobia e o grau de naturalidade de ecossistemas urbanizados. Anais ... VI CONGRESSO DE ECOLOGIA DO BRASIL. Fortaleza, 2003, p. 110-112.

ODUM, E.P. Ecologia. Rio de Janeiro: Guanabara, 1983, 434p.

PEARSON, S.M. Interprerting landscape patterns from organism-based perspectives. In: GERGEL, S.E.; TURNER, M.G. (Eds.) Learning Landscape Ecology. A practical guide to concepts and techniques. New York: Spring-Verlag, 2002, p. 187-198

SUKOPP, H. Wandel von Flora und Vegetation in Mitteleuropa unter dem Einfluss des Menschen. Berichte uber Landwirtschaft, Bd. 50/H.1: 112-139, 1972.

SUKOPP, H.; WERNER, P. Naturaleza en las ciudades. Desarrollo de flora y fauna en áreas urbanas. Monografias de la Secretaria de Estado para las Políticas del Agua y el Medio Ambiente. Madrid: Ministério de Obras Públicas y Transportes (MOPT), 1991. 
UNESP - Universidade Estadual de São Paulo. Campus Rio Claro. Departamento de Ecologia. Disponível em: http://ns.rc.unesp.br/ib/ecologia/ Acesso em: maio de 2004.

ZONNEVELD, I.S. Scope and concepts of landscape ecology as na emerging science. In: Zonneveld \& Forman (eds.) Changing Landscapes: an ecological perspective. Berlin: Spring-Verlag, 1990, 286p.

\section{ANEXO 1}

Segundo a Resolução $\mathrm{n}^{\mathrm{o}} 5$ de 02.09.1996 (DOU), as áreas de atividades previstas para a Ecologia são as seguintes: Ecologia Vegetal, Ecologia Animal, Ecologia de Solos, Ecologia Marinha, Ecologia de Microorganismo, Ecologia Aplicada, Ecologia de Populações, Ecologia de Comunidades, Ecologia Energética, Ecologia de Ecossistemas, Ecologia Costeira, Tecnologia Ambiental, Recuperação de Ecossistemas, Análise de Ecossistemas, Manejo de Ecossistemas Naturais e Artificiais, Paleoecologia, Preservação e Conservação de Recursos Naturais, Limnologia, Ecologia de Estuários, Ecologia Humana, Planejamento Ambiental, Controle de Poluição, Reciclagem de Resíduos Orgânicos, Manejo de Recursos Naturais Renováveis, Controle de Pragas em Cultivos Vegetais, Toxicologia dos Pesticidas, Controle Químico, Biológico e Integrado de Pragas, Biologia Sanitária e Ambiental, Banco de Amostras Ambientais, Monitoramento de Recursos Bióticos, Dinâmica de Populações, Monitoramento de Recursos Hídricos, Monitoramento Biológico, Controle e Monitoramento Ambiental, Biolixiviação, Vermicompostagem e Compostagem.

\section{ANEXO 2}

Segundo Resolução n. 10 de 05.07.2003 (DOU), as atividades, áreas e subáreas do conhecimento do Biólogo (...) item 2.7 Ecologia: Ecologia aplicada, Ecologia evolutiva, Ecologia humana, Ecologia de ecossistemas, Ecologia de populações, Ecologia da paisagem, Ecologia teórica, Bioclimatologia, Bioespeleologia, Biogeografia, Biogeoquímica, Ecofisiologia, Ecotoxicologia, Etnobiologia, Etologia, Fitossociologia, Legislação ambiental, Limnologia, Manejo e conservação, Meio Ambiente, Gestão Ambiental.

\section{ANEXO 3 \\ Programação parcial do I Fórum de Debates ECOLOGIA DA PAISAGEM E PLANEJAMENTO AMBIENTAL}

Período: de 04 a 08 de junho de 2000

Local: Horto Florestal Navarro de Andrade e Instituto Biociências/Unesp - Rio Claro/SP Brasil.

Público-Alvo: profissionais de universidades, Arquitetura, Biologia, Ecologia, Engenharia (Agronômica, Civil, Florestal, outras), Geografia, Geoecologia, Sociologia, Urbanismo, 
Serviços Públicos Federais, Estaduais e Municipais, Escritórios de Planejamento, Empresas Construtoras e Alunos de Graduação e de Pós-graduação.

Realização:

SEB - Sociedade de Ecologia do Brasil

CEA - Centro de Estudos Ambientais - Unesp

IB - Instituto de Biociências - USP

IGCE - Instituto de Geociências e Ciências Exatas - Unesp

CEAPLA - Centro de Análise e Planejamento Ambiental - Unesp

FFLCH - Faculdade de Filosofia, Letras e Ciências Humanas - USP

PPG-ERN/UFSCar - Programa de Pós-graduação em Ecologia e Recursos Naturais

IF - Instituto Florestal - SMA

PMRC - Prefeitura Municipal de Rio Claro

SBAU - Sociedade Brasileira de Arborização Urbana

Programa (principais palestras e convidados):

Ecologia da Paisagem: uma restrospectiva - Helmut Troppmair (Unesp - Rio Claro/SP).

Questões Ambientais no Brasil - Carlos Augusto Figueiredo Monteiro (USP - São Paulo/SP).

Agenda 21 - Peter Meyer (Parlamento da Alemanha).

O Alcance Profissional da Jardinocultura e Desenvolvimento de Espaços Livres na Alemanha - Gert Gröning (Universidade de Artes de Berlim - Alemanha).

Cartografia de Biótopos - Markus Weber (Grupo Brandt Meio Ambiente - Belo Horizonte/MG).

Considerações sobre Preferências Culturais e Propostas para Planejamento Ambiental Henri Décamps (Universidade de Toulouse - França).

Parque Ecológico do Tietê: para contornar problemas de inundação em São Paulo (Ruy Ohtake).

Instabilidade de Vertentes em Áreas Tropicais - Lylian Coltrinari (USP - São Paulo/SP). 